\title{
ALGUNOS FRAGMENTOS ALJAMIADOS DEL PROCESO INQUISITORIAL CONTRA YUÇE DE LA VAÇIA, ALFAQUÍ DE LA VILLA DE MOLINA (1495)
}

\section{INTRODUCCIÓN}

En el Instituto Miguel Asín, Escuela de Estudios Árabes de Madrid, se conservan (carpeta XCIX núm. 3) cuatro fragmentos de papel que aparecieron, según consta en Catálogo ${ }^{1}$ en las cubiertas del ms. núm. XXXV, procedente del hallazgo de Almonacid de la Sierra.

Su estado de conservación es bastante malo: el papel está oscurecido y apolillado y además ha sido recortado para su aprovechamiento en la encuadernación. Todos los fragmentos están escritos por ambas caras, en tinta negra, con la letra característica de los textos aljamiados y por una sola mano. Se trata de algunos trozos de una copia de la sentencia del proceso inquisitorial contra Yuce de la Vacía, moro alfaquí de la villa de Molina de Aragón, procesado y penitenciado por el tribunal de Sigüenza en 1495.

Que sepamos, es el único documento de este tipo (transcripción aljamiada de un documento inquisitorial) que se conoce; su interés indudable se ve, a nuestro parecer, aumentado por el hecho de que se conserva, por otra parte, entre los fondos del Tribunal de la Inquisición de Cuenca, el proceso original contra Yuce de la Vacía y la sentencia completa de que los fragmentos aljamiados son fiel transcripción.

EL PROCESO

El proceso inquisitorial contra Yuce de la Vacía conservado en el Archivo Diocesano Conquense ${ }^{2}$ constituye por sí solo un documento excepcional, único en lo que a Castilla se refiere.

1 J. RIBERA y M. ASIN, Manuscritos árabes y aljamiados de la Biblioteca de la Junta, aadrid, 1912, p. 255.

2 ADC, Leg. 19 núm. 344. 
Hasta el momento en que fueron convertidos al cristianismo (1501 en el caso de los mudéjares castellanos), la Inquisición no pudo intervenir en contra de judíos ni de moros salvo en los casos bien especificados de proselitismo o sacrilegio. En las tranquilas y poco numerosas morerías castellanas, muy integradas desde antiguo en la población local, puede decirse que dichos casos son prácticamente inexistentes, como lo son a su vez los procesos a judíos no bautizados ${ }^{3}$.

El proceso contra Yuçe de la Vacía, pues, debió de tener en su momento su pequeña repercusión local, no sólo por lo poco habitual del caso, sino por tratarse de un alfaquí, es decir, la personalidad más destacada de las aljamas mudéjares y además perteneciente a una de las morerías más considerables del Obispado de Sigüenza. En el norte de dicho obispado y en particular en torno al valle del Jalón existía un grupo de morerías importantes y en estrecho contacto con Aragón. Los procesos incoados a moriscos de estas localidades con posterioridad a la conversión dan fe de que en esta comarca el Islam mudéjar se hallaba menos limado que en otras regiones castellanas ${ }^{4}$. Las relaciones constantes con Aragón, también abundantemente atestiguadas (el hecho de que el documento aljamiado a que nos referimos se encontrara en Aragón es otro dato en el mismo sentido) explican la vitalidad del mudejarismo en esta zona. De este grupo de morerías Molina actuaba a modo de "capital": tenía una importante mezquita frecuentada por los habitantes de las morerías vecinas y su aljama era una de las más numerosas de la comarca ${ }^{5}$.

Por desgracia, el proceso - uno de los más antiguos de los conservados en los fondos de los Tribunales de Cuenca y Sigüenzaestá incompleto. Falta toda la parte primera hasta la acusación del fiscal $^{6}$, lo cual significa que se han perdido las relaciones, la orden de prendimiento y las primeras audiencias con el acusado, particularmente interesantes, pues en ellas éste solía declarar su genealogía y relatar el "discurso de su vida".

3 También lo fueron en otros reinos: a título excepcional la Inquisición de Valencia, deseosa de intervenir en el control de los moros, se arrogaba en 1498 jurisdicción sobre la guarda de las leyes de diferencias en el vestido y lugares de residencia, por lo que fue inmediatamente llamada al orden por Fernando el Católico (cf. H. Ch. LEA, The moriscos of Spain: their conversion and expulsion, Nueva York, 1968, p. 27).

${ }^{4}$ CF. M. GARCIA-ARENAL, Inquisición y moriscos: los procesos del Tribunal de Cuenca, Madrid, 1978.

5 M. A. Ladero Quesada ha calculado, por medio de un tributo extraordinario que fue repartido entre las aljamas castellanas a lo largo de diversos años de finales del siglo, el número aproximado de familias que las habitaban. Según estos datos, la aljama de Molina contaba en 1495 con 43 familias, siendo sólo superada por Deza, con 47 (Cf. su libro Los mudéjares de Castilla en tiempos de Isabel 1, Valladolid, 1969, pp. 17-20).

${ }^{6}$ Que fue publicada por M. GARCIA-ARENAL, op. cit., p. 119. 
La acusación principal contra Yuçe es la de hacer proselitismo: intentaba supuestamente convencer a cristianos de que cambiaran de religión y les invitaba a la mezquita a oír sus sermones, amén de proferir frases en menosprecio de la ley cristiana como suponer que sólo se puede ser cristiano por ignorancia y falta de información -que él estaba dispuesto a suplir- o que incluso la ley de los judíos era mejor que la de los cristianos.

En las diversas audiencias que con él se tienen a raíz de la acusación del fiscal, Yuçe declara en su defensa "que algunos christianos de la dicha villa avían dicho en mi presencia muchas palabras ynjuriosas contra my ley... y muchas deshonestidades contra Mahomad" a las cuales, y a otras agresiones, se había sentido obligado a responder. Además les exhortaban continuamente, a él y a sus seguidores, a que se hicieran cristianos, diciéndole "que entonces iría al Paraíso". Para ello le decian "que quatro alfaquís de Granada se abían convertido al Christianismo", a lo cual había replicado "que un fraile se había tornado moro en Granada" y que "bolberse moros christianos e christianos moros" no significaba nada. También alega que había cristianos que le habían venido con dudas a las que él había respondido, y que no había convidado a nadie a oír sus sermones sino "que él predicaba en la mezquita con las puertas abiertas". Y otras contestaciones de este tenor.

Tanto en las agresiones como en las defensas se hacen numerosas referencias a Granada donde, recién terminada la guerra, estaban empezando a efectuarse los primeros intentos de conversión en masa. No cabe duda de que la situación granadina influye decisivamente no sólo en la actuación de Yuçe y en la de sus vecinos cristianos, sino también en el hecho de su proceso inquisitorial.

Es también curiosa la supuesta afirmación de Yuçe de que "la ley de los judíos era buena e que aquella él la defendería": los otros dos procesos que se conservan en Cuenca incoados a mudéjares y anteriores a 1502 son los de Catalina López, también de Molina (1496) y Alonso Díaz de Belinchón, (1499) y y a ambos se les procesa no por su calidad de moros ni por las dos faltas mencionadas de proselitismo o sacrilegio que hubieran podido cometer como tales, sino por judaizantes, acusados de realizar prácticas más o menos sincréticas (los judios entran dentro de la jurisdicción de la Inquisición como herejes y apóstatas a partir de 1492). El dato es significativo de cómo estos mudéjares que, para utilizar una frase de Halperin Donghi, "no sabían ser moros ni cristianos", para suplir prácticas o ritos religiosos a menudo olvidados recurrían a otros que, como los suyos, estuviesen enfrentados al catolicismo oficial ${ }^{8}$.

\footnotetext{
7 ADC leg. 21 núm. 385 y leg 30 núm. 523 respectivamente.

\& Como ocurriría algo más tarde con el protestantismo. Cf. L. CARDAILlAC, "Morisques et protestants", $A l A n, 36$ (1971), 26-63.
} 


\section{LA SENTENCIA}

Editamos a continuación las dos versiones de la sentencia del proceso.

El orden en que deben leerse los fragmentos aljamiados para obtener un texto muy incompleto pero seguido es: $1 \mathrm{r}, 2 \mathrm{r}, 1 \mathrm{v}, 2 \mathrm{v}, 3 \mathrm{r}$, $4 \mathrm{r}, 3 \mathrm{v}, 4 \mathrm{v}$, lo cual sugiere que originariamente los números $1(10,5 \times$ $14 \mathrm{cms}$.) y $2(10,5 \times 7,5 \mathrm{cms}$.) pertenecían a una misma hoja y los números $3(10,5 \times 7 \mathrm{cms}$.) y $4(10,5 \times 5,5 \mathrm{cms}$.) a otra.

En la edición se ha respetado la grafía del original salvo algunas excepciones: se ha transcrito $>\overline{\mathrm{a}}<$ por $e$ y la $>\mathrm{u}<$ como $o$ o $u$ según convenía; en lugar de $>\mathrm{b}<,>\mathrm{l}<, \mathrm{y}>\mathrm{n}<$ con tašdïd hemos puesto, respectivamente, $p, l l$ y $\tilde{n}$.

Como podrá verse, la transcripción aljamiada es absolutamente literal y hecha además con tal intención, puesto que las palabras que el transcriptor considera difíciles o ininteligibles para los lectores a quienes va destinada no se sustituyen sino que se explican en notas interlineales. Tan sólo hay una diferencia con el documento original: la que se encuentra en el primer fragmento aljamiado, donde se hace referencia a Pedro de Ledesma, notario. De lo cual puede deducirse que la transcripción fue hecha no a partir de la sentencia original sino de una copia notarial de ésta.

La cuestión inmediata es cuál sería el objeto de esta copia notarial y cómo llegó a manos de los mudéjares. El caso es absolutamente excepcional. Parece evidente que la Inquisición proporcionó una copia oficial de la sentencia bien al propio reo o bien -y quizá más probable - a las autoridades de la aljama de Molina, ya que los mudéjares todavía tenían la capacidad de regirse por sus propios tribunales. Tal vez el hecho tuviese también una intención ejemplar. En cualquier caso debe quedar como hipótesis, pues no se conoce ningún otro caso en que esto haya sucedido, ya sea con judíos ya con moros, ni hemos encontrado ninguna provisión legal ni de la Inquisición que justifique el hecho ni haga pensar que en algún momento fue habitual. Tan sólo muy posteriormente (en los siglos XVII y XVIHI) se encuentran algunos casos en que se proporciona al reo un resumen hecho por notario de la sentencia, en casos en que ésta suponía destierro temporal, para que los inculpados pudieran enseñarla cuando deseasen volver a su tierra una vez pasado el plazo del destierro. Yuçe, en efecto, fue desterrado "del reino de Castilla”, pero de por vida. La copia notarial de que tratamos debió, pues, tener otra finalidad.

ADC leg. 19 núm. 344

"En la çibdad de Sygüença, en diez y siete días del mes de nobiembre, año de myll e quatro-
EEA, carpeta XCIX núm. 3

$/$ [a]l-ḥamdu li-llāh wahdahu [1 r] en-la-sibdad de Siwensa a dizišiyete diyaš d-el-mes [de] 
cientos e nobenta e çinco años. $\quad / 2[$ no]biyenbere año del-nasimiyento de nuwestoro salbador Yesuk[risto] $/{ }^{3}$ de mil i kuwatrosiyentos [nobenta] i sinko años

estando los Reverendos Señores el liçenciado Ferrando de Parra e el bachiller Pero Gonzalbes de Aguilera, Inquisidores,

e estando presente Yuçe de la Vaçía, moro alfaquí de la villa de Molina, sus Reberencias, por un escrito que en sus manos tenían dieron e pronunciaron una sentencia el tenor de la qual de verbo ad verbum, es éste que se sigue:

Nos, el licenciado Ferrando de Para e el bachiller Pedro Gonzalbes de Aguilera, juezes inquisidores de la herética pravedad e apostasía de la çibdad e obispado de Sigüença, dados y nombrados por los muy reverendos e muy magníficos señores el arzobispo de Mesina e el obispo de Avila del consejo del Rey la Reina nuestros señores, ynquisidores generales de la herética pravedad e apostasía en todos los reynos e señoríos de sus altezas por la autoridad apostólica, visto e con diligencia examinado un proceso de pleito pendiente ante nos entre partes, conviene a estando [los] / ${ }^{4}$ rreberendos šeñores enkišidores el-lisensiyado Her[nando] ${ }^{/ 5}$ de Para i el-bayiller Pero Gonsalbes d-Agilera en su-'awdensiya /6en-perešensiya de mi[cer] Pedro de Ledesma notaryo del sek[reto] $/ 7$ del-ofisyo de la-santa enkesisiyon en-la-diýa sibdat $/{ }^{8} \mathbf{i}$ obispado de Siwensa i obispado i de los [. . . ] $/{ }^{9}$ debašo eskiribtos estando peresente Yuse Labaziya moro[ro] $/{ }^{10}$ [alfaqi] en la billa de Molina, loš diŷos señores [. . . ]//

$/{ }^{1}$ kuwal de berbo ad berbun ${ }^{9}$

$/ 2 e$ muy manifikos ${ }^{10}$

${ }^{/ 3}$ do de Para e el-bayiyer Pero Gon

${ }^{4}$ reš de la eretika parabedat ${ }^{11}$

$/ 5 i$ obispado de Siwensa dado[s]

$/{ }^{6}$ berendošs ${ }^{12}$ šeñores ell-arsobi[spo]

$/ 7$ Abila del-konšeso del rrey

/8šeñores, enkišidores

$/{ }^{\circ}$ bedat e apostasiya [en]//

$/ 1$ todos los reynos e señor [iyos] [l v ] de sus altezas por l-awtorida[d]

$/ 2$ a ]poštolika

bišto i kon-deliyensiya es-aminado un-porose[ $\left[\right.$ so $^{/ 3}{ }^{\text {s }}[\mathrm{d}] \mathrm{e}$ peleyto pendiyent [ante] nos entere partes $/{ }^{4}$ konbiyene a

\footnotetext{
9 Debajo de esta línea pone: "li-llăhi-l-hamd wa-l-sukr".

10 A continuación: " $a$ ' ni haziyenteš kosas garandeš".

11 Sobre esta palabra: " $a$ c $n \bar{i}$ maleza".

12 Sobre esta palabra: "de garan akatamiyento e muy maknifikos".
} 
saber, de la una el venerable bachiller de la Vega, promotor fiscal del Oficio de la Santa Inquisición de la dicha cibdad y obispado, autor demandante, e de la otra Yuçe de la Vacía, moro alfaquí de la villa de Molina de esta diócesis e su procurador en su nombre, reo defendiente, e vista una acusación e demanda que contra el dicho Yuçe el dicho promotor fiscal puso, en que en efecto dixo que el dicho Yuçe con persuasión diabólica a procurado de induzir e atraer algunos christianos a que se bolbiesen a la ley de los moros esecta de Mahoma diziendo que aquella era la berdadera ley en que los onbres se avían de salvar, e que la ley de los christianos era falsa e que sy lo christianos conociesen la falsedad de su ley luego se tornarían todos moros e que él conocía algunos sabios christianos que conociendo la falsedad que tenían ante la berdad de la seta de Mahoma se avían buelto moros, otras veces dixera que la ley de los judíos era buena e que aquella él la defendería, e burlando de la ley de Ihesu Christo muchas veces decía que los christianos adoravan en ymágenes e los moros a Dios, e por mejor atraer a su seta a los christianos les conbinaba e rrogava saber de la-una el benerable bayiller de la-Be[ga] $/ 5$ [po]romotor fiskal ${ }^{13}$ del-ofisyo de la šanta enkišisiyon en la di[cha] $/{ }^{6}$ sibdad i obišpado aktor ${ }^{14}$ demandante i de la otra Yusuf $/ 7[d]$ e la Baziya moro alfaqí en la bila de Molina d-esta-diyosisi ${ }^{15}$ de $/{ }^{8}$ su-porokurador en su nonbere, rreo $^{16}$ defendiyente $/ 9[\ldots]$ akušasiyon $[\ldots] /$

$/ 1$ en-ke-en-afeto disó ke [2 v.] $/{ }^{2}$ persuašiyon ${ }^{17}$ diyabolika

$/{ }^{3} \mathrm{i}$ ataraer a algunos kiri

$/^{4} \mathrm{a}$ la ley de los moros e se[ta]

$/{ }^{5} \mathrm{ke}$ akella era la-berdadera

$/{ }^{6}$ reš sabiyan de šalbar $\mathrm{e}$

$/ 7$ era falša e ke še los̀ $\mathbf{k}$

/8la-falsedad de su-ley luwe

$/ 9 \mathrm{e}$ k-el konosiya algunoš //

${ }^{/ 1}$ niyan a la-berdat de la-šeta

${ }^{2} \mathrm{~s}$, e otras bezes

$/{ }^{3}$ yoš era buwena e ke ake

$/^{4}$ de la-ley de Yesukirišto

/5kiristiyanos adoraban

$/ 6 \check{\mathbf{s}}$, e por mišor ataraer

$/ 7$ los konbidaba e rrogaba

13 Sobre esta palabra: " $a^{c} n \bar{\imath}$ promobedor akušant".

${ }^{14}$ Sobre esta palabra: " $a c n \bar{\imath}$ hazedor".

15 Sobre esta palabra: " $a c n \bar{\imath}$ obišpado".

${ }^{16}$ Sobre esta palabra: " $a^{c}$ ni kulpado".

17 Sobre esta palabra " $a^{c} n \bar{\imath}$ moneštamiyento". 
que fuesen a oír sus

sermones a la mezquita, de lo qual todo el suso dicho Yuçe rresultava aver seydo defensor e fautor de hereges e domatizador de la seta de Mahoma, e aver atraydo e sosacado a muchos christianos a que fuesen moros e guardasen la ley de los moros, e aver fecho e cometido otros muchos rrietos en oprobio e menosprecio de Nuestra Santa Fee Cathólica e ley evangélica, por que nos pedía procurásemos e declarásemos el dicho Yuce aver sevdo defensor e fautor de hereges e domatizador de la dicha seta de Mahomad e atrator de los christianos e persuasor dellos a los atraer e conbertir a la dicha ley de los moros e aver caydo en confiscación e perdimiento de todos sus bienes desde el día en que por el suso dicho los dichos delitos fueron cometydos, e en todas las otras penas civiles $\mathrm{e}$ criminales contra tales domatizadores e persuasores en derecho establecidas, $\mathrm{e}$ atento como por nos le fue mandado dar copia de la dicha acusación al dicho Yuçe. e visto todo aquello que contra ella quiso decir e alegar fasta que ambas las dichas partes concluyeron e como por nos fueron rrecibidas a su prueva todo aquello que orovado les podiese aprovechar, e como par nos fue fecha publicación de los testigos por ambas las dichas partes presentadas
$/^{8}$ rmoneš a la meskita

$/ 9\left[\right.$ Yusuf resultaba $\left.{ }^{18}\right] / /$

/'ŷyeš e domatizador

$/ 2$ ido e susušakado

${ }^{13}$ moroš e wardašen

$/ 4$ e kometido otroš

$/{ }^{3}$ ošperesyo ${ }^{19}$ de nuwe

$/ 6$ lika por ke noš

$/{ }^{7}$ suf aber šeido

$/ 8 \mathrm{e}$ domatizador de la-šeta //

$/ 1$ de loš kirištiyanoš i

$/^{2}$ ed konbertir a la-di

$/{ }^{3}$ en kušfiškasiyon

$/ 4$ biyeneš dešde

${ }^{5}$ diŷoš delitoš fuw

$/ 6$ otraš penaš sebi

$/ 7$ domatizadoreš ed pe

$/ 8$ establešidas $\mathrm{e}$

${ }^{9} \mathrm{dar}$ kopya (de todo akello)

$/{ }^{10} \mathrm{e}$ bišto todo akello ke ko //

$/{ }^{1}$ por noš fuwe re

$/ 2$ ke porobado le

$/{ }^{1}$ fuwe feŷa publi

$/ 4$ laš diŷaš parteš

18 Sobre esta palabra -ahora perdida-: " $a^{c} n \bar{\imath}$ šentendiya".

19 Sobre esta palabra: "[ . . .]sto". 
e todo lo que ambas las dichas partes contra los dichos testigos quisieron allegar e contra decir fasta que otra segunda vez concluyeron e nos pidieron sentencia definitiva, e como nos concluymos con ellos e ovymos el pleito por concluso e las rrasones del por cerradas, e como por nos fue asynado término para dar sentencia para dia cierto e dende en adelante para cada y cuando que deliberado toviésemos e bien visto nos fuese para lo qual ver e pronunciar, por nos fueron citadas las dichas partes e avido sobre todo nuestra deliberación e acuerdo con letrados de muchas letras e conciencia, e aviendo a Dios ante nuestros ojos:

/5allegar e kontara de

$/{ }^{6}$ konkuluyeron

$/$ 'ed komo noš konk

$/^{8}$ kulušo e-laš rrazone

$/ 9$ termino para dar ̌̀

$/ 10$ anadelante para $\mathbf{k}$

/ubišto noš fuwe.

Fallamos que atentos los meritos de lo procesado a las confesyones por el dicho Yuçe de la Vasía fechas, que le devemos condenar e condenamos a que sea traydo a la verguença públicamente por la villa de Molina por los lugares donde se acostumbran traer a aquellos a que se hase justicia, de esta manera, encima de un asno, desnudo de las espaldas con la camisa vestida e una soga desparto a la garganta e un mordaza a la lengua e sin bone [te] e atadas las manos e que dé e pague para ayuda e sustentación a los gastos del Oficio de la Santa Inquisyción cinquenta florines de oro los quales luego dé e pague al receptor, de sus alcances, e que sea desterrado de los Reynos e señoríos de Castilla perpetuamente e que en ellos no entre so pena de muerte e así lo pronunciamos e mandamos le detenga en la carcel fasta que aya dado e pagado los dichos florines.

\section{EsTUDIo LINGürstico}

VOCALES ${ }^{20}$

\section{Iniciales o aisladas}

/a/ se representa mediante alif con fatha, sin hamza;

/i/ mediante alif con Kasra, sin hamza;

/e/ mediante fatha sobre hamza sin soporte, seguida de alif de prolongación;

/o/ y /u/ mediante damma sobre hamza con soporte $w \bar{a} w$.

20 La transcripción de las vocales es muy similar a la empleada por otros textos aljamiados aragoneses y castellanos. Compárese, por ejemplo, con R. MENÉNDEZ PIDAL, Poema de 


\section{Mediales o finales}

$/ \mathrm{a} /=$ fatha; $/ e /=$ fatha seguida de alif de prolongación; /i/ =Kasra; /o/ y /u/ = damma.

No se utilizan las vocales largas excepto en el caso de $>a<=$ /e/, equivalencia usual del aljamiado aragonés, en la palabra árabe a'n1 y en $>$ alfaqi $<$.

\section{Anaptixis $^{21}$}

El texto utiliza sistemáticamente vocales anaptícticas para evitar el concurso de dos consonantes en principio de palabra o tras sílaba cerrada, concurso que en castellano se da casi exclusivamente con los grupos formados por oclusiva seguida de líquida:

$/ \mathrm{br} /:>$ nonbere $<(\mathbf{l v}),>$ [no]biyenbere $<(1 \mathrm{r})$

$/$ pr $/:>$ porobado $<(4 \mathrm{v}),>$ parabedat $<(2 \mathrm{r}),>[$ men]ošperesyo $<(4 \mathrm{r})$,

$>$ poromobedor $<(\mathrm{lv}),>$ poromotor $<(\mathrm{lv}),>$ peresente $<(\mathrm{lr})$,

$>$ porokurador $<(\mathbf{l v}),>$ porose $[$ šo $]<($ lv $),>$ perešensiya $<(\mathbf{l} \mathbf{r})$

$/ \mathrm{tr} /:>$ nuweštoro $<(1 \mathrm{r}),>$ entere $<(\mathbf{l v})$

$/$ gr/: $>$ garandes $<(2 r)$,

$/ \mathrm{kr} /:>$ kirištiyanoš $<(3 \mathrm{r}, \mathrm{v}),>$ eškiribtoš $<(\mathrm{lr})$

$/ \mathrm{pl} /:>$ peleyton $<(\mathbf{l v})$

$/ \mathrm{kl} /:>$ konkuluyeron $<(4 \mathrm{v})$.

La vocal anaptíctica aparece no sólo en los ejemplos citados, sino también alguna vez separando los mismos grupos consonánticos en condiciones que serían perfectamente, lícitas según las leyes de la sílaba árabe: $>$ ataraer $<(3 r, 2 v)$, $>$ Ýešukirišto $<(3 r)$.

Hay, por otro lado, varios contra-ejemplos en los que dichos grupos, en idénticas condiciones lícitas, son tratados sin vocal anaptíctica: $>$ kuwatrosiyentos $<($ lr $),>$ Pedro $<($ lr $),>$ sekreto $<($ lr $)$, $>$ benerable $<(\mathbf{l v})$, > otraš $<(3 \mathrm{v})$.

El panorama presentado no parece permitir pronunciarse respecto al problema de si tales vocales se deben a mera tradición

Yúçuf. Materiales para su estudio, Madrid, 1902, p. 22; ]. MARTINEZ RUIZ, "Un nuevo texto aljamiado; el recetario de sahumerios en uno de los manustritos árabes de Ocaña", en RDTP, 30 (1974), 3-17, especialmente p. 6; A. GALMES DE FUENTES. Historia de los amores de París y Viana, Madrid, 1970, pp. 152 y 161-162; A. GALMES DE FUENTES,El libro de las batallas. Narraciones épico-caballerescas, 2 ts., Madrid, 1975; J. BOSCH VILA, "Dos nuevos manuscritos y papeles sueltos de moriscos aragones" en $A l A$ n, 22 (1957), 463470; L. P. HARVEY, "Un manuscrito aljamiado en la biblioteca de la Universidad de Cambridge", $A l A$ n, 23 (1958), 49-74; L. P. "HARVEY, Yuse Banegas. Un moro noble en Granada bajo los Reyes Católicos. Extracto del ms. aljamiado de la Biblioteca Nacional de Madrid, Res. 245"', AlAn, 21 (1956), 297-302.

${ }^{21}$ Sobre este tema y para más ejemplos, véase Yúçuf, p. 23; Sahumerios, p, 6; París, p. 162-163; Batallas, t. 1. passim; M.ALVAR y F. DE LA GRANJA, "Apostillas lingüísticas al «Fecho de Buluqiya», en Homenaje a Francisco Ynduráin, Zaragoza, 1972, pp. 23-39, especialmente pp. 25-26. 
gráfica, basada en la estructura de la sílaba árabe, o corresponden a un valor articulado ${ }^{22}$

\section{Epéntesis $^{23}$}

$I$ y $u$ semiconsonantes o semivocales son sentidas en árabe como consonantes y como tal tratadas en aljamiado. Esto lleva en algunos casos a la formación de grupos de dos consonantes en principio de palabra o tras sílabas cerrada que, como acabamos de ver, se resuelven mediante una vocal anaptíctica, en este caso análoga a la semiconsonante: $>$ lisensiyado $<(1 \mathrm{r}),>$ awdensiya $<(1 \mathrm{r}),>$ perešensiya $<$ (lr), $>$ nuweštoro $<$ (lr), $>$ diyušisi $<$ (lr), $>$ defediyente $<$ (lv), $>$ luwe[go] $<(2 \mathrm{v}),>$ buwena $<(3 \mathrm{r})$, $>$ kirištiyanoš $<(3 \mathrm{r}, \mathrm{v}),>$ biyeneš $<(3 v), \quad>$ fuwe $<(4 v),>$ deliŷensiya $<(1 \mathrm{v}),>$ konbiyene $<$ (lv).

El mismo recurso aparece empleado en los casos en que la segunda vocal del grupo es tónica, aun cuando las leyes de la sílaba árabe no exigirían la presencia de la vocal anaptíctica:

$>$ akušasiyon $<(\mathrm{lv}),>$ kuwatrosiyentoš $<(1 \mathrm{r}),>$ dizišiyete $<(1 \mathrm{r})$, $>$ nasimiyento $<(1 \mathrm{r}),>$ enkisišiyon $<(1 \mathrm{r}),>$ peršuašiyon $<(2 \mathrm{v})$, $>$ haziyenteš $<(2 r), \quad>$ kušfiskašiyon $<(3 v)$.

En la mayoría de los casos en que el encuentro de vocales es átono y tratar a $i$ y $u$ como consonantes no produce concurso de dos consonantes en la misma sílaba, la vocal anaptíctica no aparece: $>$ [men]ošperesyo $<(4 \mathrm{r}), \quad>$ notaryo $<(1 \mathrm{r}), \quad>$ ofisyo $<(1 \mathrm{r}, \mathrm{v}), \quad>$ kopya $<$ (3v), >awtoridad < (lv), >awdensiya < (lr).

Podemos hablar estrictamente de epéntesis en los casos en que la primera de las vocales del grupo es tónica. Se trata entonces de dos vocales que se hallan en sílabas contiguas. El aljamiado recurre a una consonante epentética para evitar que la segunda sílaba empiece por vocal; la consonante será $y$ o $w$ según que la vocal de la primera sílaba sea $i$ o $u$ : $>$ Baziya $<(1 \mathrm{r}, \mathrm{v})$, >šabiyan $<(2 \mathrm{v}),>$ konosiya $<(2 \mathrm{v})$, $>$ apoštašiya $<(2 r), \quad>$ diyaš $<(1 r)$.

Cuando ninguna de las dos vocales concurrentes es $i$ o $u$ se tratan las dos sílabas como si fueran dos palabras distintas: $>$ ataraer $<(3 r)$. Lo mismo ocurre, excepcionalmente, en $>$ peršuašiyon $<(2 v)$.

\section{CONSONANTES}

El $b \vec{a}^{\prime}$ transcribe el fonema castellano /b/ correspondiente a las grafías etimológicas $>\mathrm{b}<\mathrm{y}>\mathrm{v}<$. No puede hablarse en esta época

22 Según R. MENENDEZ PIDAL (Y úçuf, p. 23) no se pronunciaban. Ésta parece ser también la opinión de M. ALVAR y F. DE LA GRANJA (Buluqiya, pp. 25-26). Véase G. LABIB, "El papel de la literatura aljamiada en la transmisión de algunos aspectos estructurales de la lengua árabe sobre el aragonés", Actas del Coloquio Internacional sobre literatura aljamiada y morisca (Oviedo, 10-16 julio 1972), Madrid, 1978, pp. 337-363, especialmente pp. 352 y 362-363 en que se defiende el carácter fonético de las vocales anaptícticas.

23 Sobre este tema cf. Yúçuf, p. 23; Sahumerios, p. 6; París, pp. 163, 226; Buluqiya, pp. 26-27. 
de $/ v /$, puesto que ya no se oponía fonológicamente $\mathbf{a} / \mathbf{b} /{ }^{24}:>$ baỳiller $<(1 \mathrm{r})$, >obispado < (lr, v), >buwena $<(3 \mathrm{v}),>$ biyenes $<(3 \mathrm{v})$, $>$ berdadera $<(2 v),>$ salbar $<(2 v),>$ rreberendos $<(1 r),>$ benerable $<(\mathrm{lv}) .$.

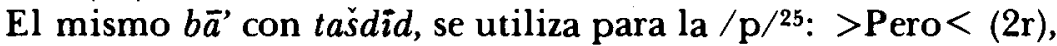
$>$ parabedat $<(2 \mathrm{r}),>$ peršuašiyon $<(2 \mathrm{v}),>$ obišpado $<(2 \mathrm{r})$, $>$ apoštašiya $<(2 \mathrm{r})$.

La $f \bar{a}^{\prime}$ representa la /f/ castellana: $>$ ofisyo $<(l \mathrm{r}),>$ fiškal $<(\mathrm{lv})$, $>$ defendiyente $<(\mathrm{lv}),>$ falša $<(2 \mathrm{v}),>$ manifikoš $<(2 \mathrm{r}),>$ fuwe $<$ (4v).

El $w \bar{a} w$ aparece en algunos casos como equivalente del grupo $\mathrm{g} u$, lo que sugiere tal vez una pronunciación fricativa de $/ \mathrm{g} /{ }^{26}$ : $>$ wardašean $<(4 \mathrm{r}),>$ Siwensa $<(1 \mathrm{r})$.

$\mathrm{La} / \mathrm{t} /$ se representa con $t \bar{a}^{2} \mathrm{y}$ la $/ \mathrm{d} /$ con $d \bar{a} l$ tanto cuando se trata de $[\mathrm{d}]$ como de $[\mathrm{d}]:>>$ defendiyente $<(1 \mathrm{r}),>$ berdadera $<\left(2 \mathrm{v}^{\prime}\right)^{27}$. . .

La nün con tašdid transcribe el sonido castellano $\tilde{n}^{28}:>$ año $<$ (1r), > señores < (lr, 2v). Y el lām con tašdïd la $l l^{29}:>$ akello< $(3 \mathrm{v})$, $>$ bayiller $<{ }^{30}(1 \mathrm{r}),>$ billa $<(\mathrm{lr})$.

$\mathrm{La} / \mathrm{r} /$, representada por $r \bar{a}$, acostumbra a llevar $t a \check{s} d \bar{i} d^{31}$ cuando es inicial de palabra para indicar su realización como vibrante múltiple: $>$ rry $<(2 \mathrm{r}),>$ rreberendos $<(1 \mathrm{r}),>$ rrogaba $<(3 \mathrm{r}),>$ rrazo neš $<(4 v)$.

El $k a ̄ f$ se utiliza para la totalidad del fonema castellano $/ \mathbf{k} /$ : $>$ kuwatrosiyentos $<(\mathrm{lr}),>$ apostolika $<(\mathrm{lv}),>\mathrm{ke}<(2 \mathrm{v})$. El $q \bar{a} f$ se emplea únicamente en el arabismo $>$ alfaqï $<(\mathrm{lv})^{32}$.

${ }^{24}$ C. Yúguf, p. 24; Sahumerios, passim; Paris, p. 153; Batallas, passim; Buluqiya, p. 27. Véase la vacilación en el uso de $b$ y $z$ en el texto en caracteres latinos de la acusación de este mismo proceso en M. GARCîA-ARENAL, op. cit., pp. 119.120.

${ }_{25}$ No todos los textos aljamiados utilizan el tašdid para $/ \mathrm{p} /$. Entre los que no lo emplean están Buluqiya y Sahumerios. Sobre el problema de si la neutralización de la oposición $b \neq p$ era sólo gráfica o correspondía a la pronunciación, véase Yúçuf, p. 25 y A. E. SLOMAN, "The phonology of moorish jargon in the works of early Spanish dramatistis and Lope de Vega", $M L R, 44$ (1949), p. 211; sobre el tašdid en aljamiado, U. KLENK, "El 'tašdïd' en la «leyenda de Yūsuf» manuscrito aljamiado", Actas del Coloquio Internacional sobre literatura aljamiada y morisca (Oviedo, 10-16 julio 1972), Madrid, 1978, pp. 399-412.

26 Varios ejemplos en Batallas, t. 2, p. 287-289 y Buluqiya, p. 29.

${ }^{27}$ El mismo sistema en Yúcufy Buluqiya, En cambio Sahumerios y $P$ aris distinguen entre $>\mathrm{d}<=[\mathrm{d}] \mathrm{y}>\mathrm{d}<=[\mathrm{dj}$.

${ }^{28}$ Mismo sistema en Yúçuf, Sahumerios y París.

${ }^{29}$ Mismo sistema en Yúcuf, Sahumerios y París.

${ }^{30} \mathrm{La}$ forma $>$ baŷiyer $<$ (2r) que alterna en nuestro texto con $>$ bayiller < parece indicar problemas de yeísmos. Sobre este punto véase A. GALMES DE FUENTES, "Lle-yeismo y otras cuestiones lingüísticas en un relato morisco del siglo XVII", Estudios dedicados a Menéndez Pidal, Madrid, 1957, VII,pp. 273-307.

31 Cf. París, p. 155.

${ }^{32}$ Mismo sistema en Paris; Yúçuf y Sahumerios emplean $>\mathrm{q}<\mathrm{y}>\mathrm{k}<$ repartiéndose el fonema $/ \mathbf{k} /$. 
$\mathrm{La} / \mathrm{g} /$ se representa mediante el gayn: $>$ Gonsalbes $<(\mathrm{lr}),>$ rogaba $<(3 r),>$ garandeš $<(2 r),>$ garan $<(2 r)^{33}$.

Sobre el grupo gu véase lo dicho a propósito del $w \bar{a} w$. No usa las consonantes enfáticas ${ }^{34}$.

\section{Sibilantes}

En nuestro texto la pareja predorsodental se halla representada por $[\mathrm{s}]=>\mathrm{s}<\mathrm{y}[\mathrm{z}]=>\mathrm{z}<$, distinguiéndose correctamente el fonema sonoro del sordo y manteniendo la oposición respecto a las otras dos parejas de sibilantes.

[s]: $>$ nasimiyento $<(\mathrm{lr}),>$ sinko $<(\mathrm{l} \mathrm{r}),>$ lisensiyado $<(\mathrm{lr}),>$ aw densiya $<(1 \mathrm{r}),>$ ofisyo $<(\mathrm{lr}),>$ sibdat $<(1 \mathrm{r}),>$ akušasiyon $<(\mathrm{lv})$, $>$ eštablesidaš $<(3 v),>$ menošperesyo $<(4 r)$, etc.

$[\mathrm{z}]:>$ dizišiyete $<(\mathrm{lr}),>$ Labaziya $<(\mathrm{lr}, \mathrm{v}),>$ altezaš $<(\mathrm{lv})$, $>$ domatizadoreš $<(3 \mathrm{v}),>$ domatizador $<(4 \mathrm{r}),>$ rrazoneš $<(4 \mathrm{v})$, $>$ haziyenteš $<(2 r)$. . .

Hay una única excepción que se repite tres veces: el topónimo $>$ Siwensa $<$, en el que la primera $>$ s $<$ está en lugar de una $>$ s $<$. Esto puede deberse a asimilación con la segunda sibilante o indicar, tal vez, un fenómeno de ceceo ${ }^{35}$.

En la pareja ápicoalveolar se confunden el fonema sordo [š] y el sonoro [í] en un única representación $>s ̌$, en la que concurre además la prepalatal sorda [̌̌].

$[\mathbf{s}]:>$ diyaš $<(1 \mathrm{r}),>$ meš $<(1 \mathrm{r})$, >nuweštoro $<(1 \mathrm{r})$, > >štando $<(1 \mathrm{r}),>$ šu $<(1 \mathrm{r}),>$ Ledešma $<(1 \mathrm{r})$, $>$ apoštolika $<(1 \mathrm{v}),>$ šaber $<(\mathrm{lv})$, $>$ salbar $<(2 \mathrm{v})$, etc.

[ź]: >Yešuk[risto] $<(1 \mathrm{r}), \quad>$ perešente $<(1 \mathrm{r}), \quad>$ enkišisiyon $<$ (lv), >akušant $<$ (lv), >akušasiyon $<$ (lv).

En la pareja prepalatal, el fonema sordo [̌̀], trascrito por $>\check{\mathbf{s}}<$ sin tašd $\bar{i} d^{36}$, se confunde con los de la pareja ápicoalveolar: $>$ debašo $<(1 \mathrm{r}),>$ dišo $<(2 \mathrm{v})$.

El fonema sonoro $[\check{z}]$ se transcribe mediante $>\check{y}<$, signo que se

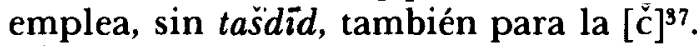

33 Igual en Yúçuf, Paris y Sahumerios.

${ }^{34}$ En la mayor parte de los textos aljamiados aragoneses las consonantes enfáticas aparecen sólo en palabras árabes. En Yúģu y Sahumerios $>\mathrm{t}<$ se reparte con $>\mathrm{t}<\mathrm{el}$ fonema $/ \mathrm{t} /$ y en Sahumerios se encuentra alguna [s] representada por $>\mathrm{s}<$.

35 A propósito del ceceo, véase Yúcuf. pp. 24-25 y DENISE CARDAlL. LAG, "Algunos problemas lingüísticos evocados a partir de los manuscritos aljamiados 4944 de la Biblioteca Nacional de Madrid y V 7 de la Real Academia de la Historia", Actas del Coloquio Internacional sobre literatura aljamiada y morisca (Oviedo, 10-16 julio 1972), Madrid, 1978, pp. 413-424.

36 Tampoco usan tašdīd con el $>\mathrm{s}<Y$ úçuf (ver p. 26) y Buluqiya (ver p. 28). Sí, en cambio, París (véanse pp. 157 y 221 ).

${ }^{37}$ Para la $[\check{c}]$ representada mediante $>\hat{y}<$ con tašdid, cf. Paris, pp. 154 y 222; Batallas, t. 2 , pp. 24-25; Yúcuf, p. 25. Sahumerios (ver p. 7) no lo emplea, y Buluqiya (ver p. 28) lo hace muy raramente. 


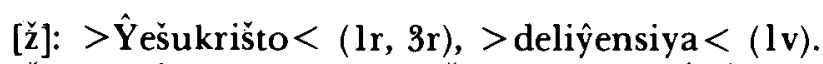
$(4 \mathrm{v})$.

$[\check{c}]:>$ baŷiller $<(\operatorname{lr}),>$ diy̌a $<(\operatorname{lr}),>$ diŷoš $<(\operatorname{lr}, 3 v),>$ feŷa $<$

Hay algunos errores en los que aparece el fonema sordo en lugar del sonoro: $>$ mišur $<(3 \mathrm{r}),>$ konšešo $<(2 \mathrm{r})^{\mathbf{3 8}}$.

Este sistema de transcripción de las sibilantes es el habitual en la mayor parte de los textos aljamiados ${ }^{39}$.

No merecen especial comentario las asimilaciones $>$ šabiyan $<$ (= se habian) (2v) y $>$ diagilera $<$ (= de Aguilera) (lr).

Las formas $>$ manifikoš $<(2 r)$ que alterna con la correcta $>$ maknifikoš $<(2 \mathrm{r})$ y $>$ kušfiškasiyon $<(3 \mathrm{v})$ parecen deberse más a desconocimiento de los términos que a fenómenos lingüísticos.

\section{LAS NOTAS INTERLINEALES}

Llama la atención la presencia de una serie de notas interlineales - de mano del copista - destinadas a explicar el significado de determinadas palabras empleadas en el tex to inquisitorial, generalmente términos legales. Las glosas van introducidas por la palabra árabe $a^{c} n \bar{\imath}$ (quiero decir) y tienen especial interés por cuanto ellas -y no las expresiones estereotipadas del formulario procesal - pueden permitir conocer algo de las características lingüísticas del transcriptor.

Las palabras "difíciles" y sus explicaciones son:

\begin{tabular}{|c|c|}
\hline \multirow[b]{2}{*}{$\begin{array}{l}\text { poromotor fiškal } \\
\text { aktor }\end{array}$} & \multirow[b]{2}{*}{ poromobedor akušant } \\
\hline & \\
\hline diyosiši & obišpado \\
\hline rreo & kulpado \\
\hline [resultaba] & šentendiya \\
\hline peršuašiyon & monestamiyento \\
\hline manifikoš & haziyenteš košaš garandeš \\
\hline parabedat & maleza \\
\hline [re]berendoš & $\begin{array}{l}\text { [. . .] de garan akatamiyento e } \\
\text { muy maknifikoš }\end{array}$ \\
\hline
\end{tabular}

Hay además dos jaculatorias en árabe: al-hamdu li-llāhi wahdahu (alabado sea Dios único; lr), y li-llāhi-l-haamd wa-l-šukr (alabanza y gracias a Dios; 2 r).

La pervivencia en el texto de algunos grupos consonánticos que la lengua española había ya simplificado: $>\operatorname{sibdad}<(l \mathrm{r}, \mathrm{v})$, $>$ eškiribtoš $<$ (lr) y la conservación de la $f$ en $>$ fecha $<(4 v)$, que contrasta con las formas $>$ haziyentes $<$ (2r) y $>$ hazedor $<$ (lv) de las anotaciones interlineales parecen deberse a cultismo arcaizante - tal vez

38 Ejemplos similares en Batallas, t. 2, p. 22.

39 Véase otro sistema en D. CARDAILLAC, art. cit., pp. 416-418. 
simplemente gráfico- de la terminología inquisitorial, frente al habla más evolucionada reflejada por las glosas ${ }^{40}$.

\section{Aragonesismos}

A pesar de que el texto transcribe fielmente un texto castellano, pueden encontrarse algunos rasgos aragoneses: (lv).

- Pérdida de la $e$ final tras $n t^{41}>$ pendiyent $<(1 \mathrm{v}),>$ akušant $<$

- Vacilación en el timbre de las vocales átonas ${ }^{42}:>$ deliŷensiya $<$ $(\mathrm{lv})$, $>$ mišor $<(3 \mathrm{r})$, > enkesišiyon $<(\mathrm{lr})$, > enkišisiyon $<(\mathrm{lv})$, $>$ enkišidores $<(1 r, 2 r)$.

- Ensordecimiento de la consonante sonora final ${ }^{43}$ : $>$ parabedat $<$ (2r), $>$ sibdat $<($ lr $)$, >berdat $<(3 r)$.

-Palatalización de la /1/ del artículo el ante vocal ${ }^{44}$ : >ell-arsobi $[$ špo $]<(2 r)$.

\section{Influencia árabe}

No se encuentran más arabismos que $>$ alfaq $\bar{i}<$ y $>$ meskita $<$, que el castellano había adoptado ya en el siglo XIII ${ }^{45}$.

Podrían deberse a influencia árabe los participios activos en las glosas: >akušant $<\left(1 \mathrm{v}\left(,>\right.\right.$ haziyenteš $<(2 \mathrm{r})^{46}$, la creación de un sustantivo verbal mediante el sufijo-iyento: $>$ moneštamiyento $<(2 v)$, ampliamente atestiguada en otros textos ${ }^{47}$ y la formación de un sustantivo a partir de un adjetivo con el sufijo -eza: $>$ maleza $<(2 r)^{48}$.

A. LABARTA

Universidad Autónoma de Barcelona.

M. Garcia-ARENAL

Instituto Miguel Asín

Escuela de Estudios Árabes, C.S.I.C., Madrid.

4 Cf. algunos de estos mismos ejemplos y otros similares en París, pp. 224-225.

41 Cf. Batallas, t. 2, pp. 34-35; París, p. 227; Yúçuf, p. 41.

42 Cf. Batallas, t. 2, p. 37; M. AlVAR, El dialecto aragonés, Madrid, 1953, pp. 47-51.

43 Cf. Batallas, t. 2, p. 50.

4 Cf. París, p. 229; Yúcuf, p. 46; Buluqiya, p. 32.

45 Sobre alfaquí, cf. E. K. NEIVONEN, Los arabismos del español en el siglo xiii, Helsinki, 1941, p. 148, y A. S. STEIGER, Contribución a la fonética del hispano-árabe y de los arabismos en el ibero-romántico y el siciliano, Madrid, 1932, p. 274.

Sobre mezquita, cf. NEUVONEN, p. 263; STEIGER, p. 186; J. SAMSO, "Sobre la voz $>$ kanísa < en el haz dialectal hispanoárabe (con una digresión en torno a 'mezquita')", y $\mathrm{F}$. CORRIENTE, "Anotaciones al margen de kanis(iy)a y mezquita", AlAn 43 (1978), 209-224.

46 Cf. Batallas, t. 2, pp. 83-84.

47 Ver múltiples ejemplos en Batallas, t, 2, glosario.

48 Relacionable con $>$ largueza <, >garandeza <; cf; Batallas, t. 2, glosario, s.v. 
AdDendA

Cuando el presente artículo estaba ya compuesto, hemos encontrado otros dos fragmentos del documento aljamiado que editamos en él. Se conservan también en el Instituto Miguel Asín, en la carpeta LXXVII núm. 2, y - según consta en el Catálogo, p. 241aparecieron en las cubiertas del manuscrito núm. XIII, procedente del hallazgo de Almonacid.

El fragmento que hemos numerado con el núm. $5(7,5 \times 10,5$ cms.) es el que faltaba para completar las líneas del fragmento núm. 2; del mismo modo, el núm. $6(6,5 \times 10,5 \mathrm{cms}$.) viene a completar las del núm. 3. Su texto es como sigue:

Transcripción de los nuevos fragmentos [EEA, carpeta LXXVII $\left.n^{2} 2\right]$ [5r] [Alterna con 2r]

$J^{1}$ [una] šentensiya šu- tenor de [la]

$/ 2$ eš ešta ke še šige

${ }^{3}$ noš el-lisensiyado Herra[n]-

$/{ }^{4} \mathrm{~d}$-Agilera ŷuwezeš enkiši[do]-

$/{ }^{5}$ iy-apoštašiya ${ }^{1}$ en-la-sibdat

$/ 6 \mathrm{i}$ nonbaradoš por loš muy rre-

$/ 7$ de Mekrua ${ }^{2}$ i el-obišpo d[e]

$/ 8 \mathbf{i}$ de la-rreyna, nuweštoroš

$/ 9$ ŷerenaleš (sic) de eratika (sic) para-

[5v] [Alterna con 2v]

$/^{1}[\mathrm{e}] \mathrm{l}-\mathrm{di} \hat{y} o$ Yūsaf Labaziya kon

$/ 2$ abiya porokurado de induzir

/3śtiyanoš ke še bolbeiyešen

$/{ }^{4}[\mathrm{de}]$ Muhammad salla Allāhu calay-hi [wa-sallama, diziyendo]

$/ 5$ le]y en-ke loš [. . . ]

$/ 6$ ke la-ley de loš kirištiyanoš

$/ 7$ ri] štiyanoš konosiyešen

$/ 8$ go še tornariyan todoš moroš

$/ 9$ šabyoš kiristiyanoš

[6r] [Alterna con 3r]

$/{ }^{1}$ ke konosiyendo la fa

$/ 2$ de Muhammad še abiya[n]

$/ 3$ dišiyera ke la le[y]

$/{ }^{4} \mathrm{el}$ la-defenderiya

$/{ }^{5}$ muỳaš bezeš abiya

1 Sobre esta pabra: " $a c n i$ falso kereimiyento"

2 Quien hizo la copia aljamiada leyó mal la palabra "Meçina" del original, entendiendo "Mecrua", lo cual es fácilmente explicable por la proximidad en escritura gótica de ambas grafías. 
${ }^{6}{ }^{\mathrm{e}}$-imaŷeneš e loš

$/ 7$ a šu-šeta a loš ki

$/ 8$ ke fuwesen a oir

$/{ }^{9} \mathrm{de}$ lo-kuwal todo el

[6v] [Alterna con 3v]
$/ 1$ delloš a los ataraer
$/ 2[$ lo]š moroš e aber kaído
$/ 3$ to de todoš šuš
$/{ }^{4}$ [po]r el šušo diŷo loš
$/ 5$ doš e en todaš laš
$/ 6$ naleš kontara loš taleš
$/ 7$ š en-dereŷo
$/{ }^{6}$ por noš le fuwe mandado
$/{ }^{9}$ suf de la-diŷa akusasiyon 